\title{
PHOTOGRAPHIC OBSERVATIONS OF SOLAR SYSTEM BODIES AT THE MAIN ASTRONOMICAL OBSERVATORY OF NAS OF UKRAINE: FINAL RESULTS
}

\author{
V. Golovnia, O. Yizhakevych, S. Shatokhina, V. Andruk \\ Main Astronomical Observatory of NASU, Kyiv, Ukraine,golov@mao.kiev.ua
}

\begin{abstract}
Astrometric photographic observations of Solar system bodies in the frame of different programs were made at MAO NAN of Ukraine during 1950-2005. 9245 plates with the images of planets and their natural satellite, Moon, minor planets, comets and artificial satellites were obtained and processed in the late 20th century. At the beginning of the 21st century, the UkrVO Joint Digital Archive (JDA) was created, which is accessible at the MAO NAS resources (http://gua.db.ukr-vo.org/archivespecial.php).

To digitize the plate archive for the JDA database, flatbed scanners were used and the software was specially developed on the basis of the LINUX/MIDAS/ROMAFOT software for the processing of wide-field images, as well as searching for the images of minor planets and comets on the Northern sky survey program plates. Up to the present time, the photographic plates with images of outer planets and their satellites have been re-processed.

The final result of the long-lasting program of the photographic positional observations of Solar system bodies are summarized and presented in this publication.
\end{abstract}

Keywords: Solar system bodies, Astrometric photographic observations, UkrVO Joint Digital Archive.

\section{Introduction}

The article summarizes the results of re-processing of the old photographic observations of the Solar system bodies (SSB) at MAO NAS of Ukraine. The purpose of the observations was to obtain precise coordinates suitable for refining the SSB orbits and constructing new theories of motion, orientation of fundamental catalogs, studying the structure and evolution of the Solar system. The results, obtained by the team of the astrometry department, were the series of observations of Venus, Uranus, Neptune, Pluto, Mars, Jupiter, Saturn, natural satellites, minor planets, comets and Earth artificial satellites, which were later used for astrometric studies. The results of processing of the astrometric observations were published in different forms and placed in different sources (Onegina \& Sereda, 1971; Gavrilov \& Kislyuk, 1971; Duma \& Kizyun., 1972; Sereda \&
Izhakevich, 1978; Gavrilov et al., 1980; Kislyuk et al., 1985, 1990, 1995; Duma et al., 2000; Kizyun, 2004). A part of the observations were published in editions, which are difficult to access now, such as "Manuscripts of VINITY". Some observations still remain unpublished. Analysis of the data indicates the expediency of using of old photographic observations (Kiseleva 2007; Emelianov et al., 1999, 2006; Sergeeva et al., 2005). The modern approach to the processing of early photographic observations, which were collected in the UkrVO JDA, with new technologies is an effective tool for the reidentification of the SSB and correction of their orbits.

\section{Telescopes and astroplates' quantitative charac- teristics}

The observation of the Solar system bodies was carried out using 11 instruments. The technique and methods of observations of the SSB were various. Table 1 shows the characteristics of the used telescopes: abbreviation for the telescopes and their original name in the JDA, scale of the telescope image ("/mm), location of telescopes and periods of the observations of the SSB on the corresponding telescopes. A list of telescopes, observational archives of the JDA prototype, list of emulsions, object types, observers list can be viewed at http://gua.db.ukrvo.org/guides.php (Pakuliak, 2005, 2014; Pakuliak, Vavilova, 2014; Sergeeva, 2004, 2007, 2010).

The SSB observations were conducted with three "home" telescopes (DLA, DWA, DSA) of the Main Astronomical Observatory and seven expeditionary telescopes at Majdanak and Tashkent Observatory, Quito Astronomical Observatory and Comet Station (Ecuador), Astrophysical Observatories Abastumani and Byurakan (so-called "others" telescopes - Z-600, DAZ, CA, 2CAA, SCHC, 53/Sch and BYU (Kulyk et al., 2013). Figure 1 presents the distribution of the number of plates with the SSB according to the telescopes. As we can see 8802 plates were observed with "home" telescopes for 55 years. During eight years of the expeditions to other observatories 443 plates were received on seven "others" telescopes (see Figure 1, Table 2 and Table 4). 
Table 1: List of the telescopes and periods of the observations of Solar System Bodies on the corresponding telescopes

\begin{tabular}{|l|l|l|l|l|}
\hline Abbr. & \multicolumn{1}{|c|}{ Orig. name of the Istrument } & "/mm & \multicolumn{1}{|c|}{ Observatory } & Periods \\
\hline DLA & Double Long-Focus Astrograph & 38 & Main Astron. Obs.,Kyiv, Ukraine & $1950-1986$ \\
\hline DWA & Double Wide-Angle Astrograph & 103 & Main Astron. Obs.,Kyiv, Ukraine & $1976-2005$ \\
\hline DSA & Double Short Focus Astrograph & 295 & Main Astron. Obs.,Kyiv, Ukraine & $1950-1977$ \\
\hline Z-600 & Zeiss-600 & 28 & Majdanak Obs., Mt. Majdanak, Uzbekistan & $1986-1991$ \\
\hline DAZ & Wide Angle Astrograph (Kitab) & 69.8 & Tashkent Ast. Obs. Kitab Station Uzbekistan & 1986,1988 \\
\hline CA & Ast. Photogr. Device AFU-75 & 281 & Ast. Obs. end Comet Station, Quito, Ecuador & 1986 \\
\hline 2CAA & Two-camera astrograph & 206 & Astroph. Obs. Abastumani, Kanobili, Georgia & 1990 \\
\hline SCHC & Schmidt camera & 330 & Astroph. Obs. Abastumani, Kanobili, Georgia & $1987-1990$ \\
\hline 53/Sch. & 53 cm Schmidt Telescope & 113 & Byurakan Astroph. Obs., Byurakan, Armenia & 1983,1985 \\
\hline BYU & $1 \mathrm{~m}$ Schmidt Telescope & 97 & Byurakan Astroph. Obs., Byurakan, Armenia & 1983 \\
\hline
\end{tabular}

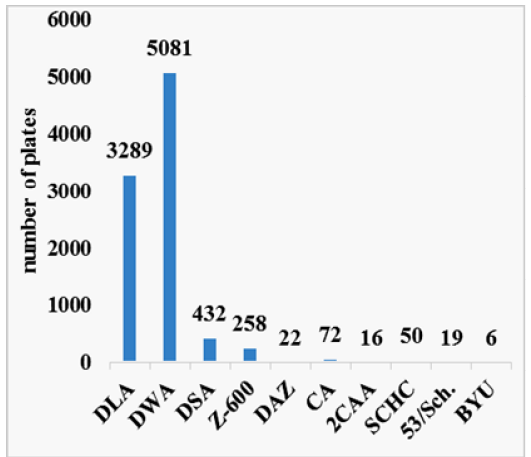

Figure 1: Distribution of the number of plates with the SSB according to the telescopes.

\section{Observational programs and observers}

Regular observations of the SSB were conducted from 1950 to 2005 under different scientific programs including "Orbit", "Faint minor planets", "Selected minor planets", "Planets and their natural satellites"; "Mars, Phobos and Deimos - 1988"; "Mars - 1990-1993"; "Mars - 19941996"; "Comets", "SOPROG”, "Moon", " Earth artificial satellites". Astrometric photographic observations of SSB began in 1950 at the astrographs DLA and DSA. First observers, I.G.Kolchinsky, T.A.Azarnova, A.A.Gorynia, R.I.Chupryna, started from the observations of the faint and selected minor planets and comets.

In Figure 2 the image of comet 2P/ Encke is presented. The comet had brightness of 17.7 magnitude and was observed by I.G.Kolchinsky.

The MAO NAS of Ukraine was the center for collecting information on the positions of comet $1 \mathrm{P} /$ Halley from around the world (Yatskiv et al., 1986; Major et al., 1987). Comet Halley was observed in the frame of the international program "International Halley Watch" and the Soviet program "SOPROG".

The plates of the Moon were obtained during the period between 1950 and 1980 with DLA to determinate its accurate position and the absolute orientation of the selenodetic reference frame.

The major planets and their natural satellites were observed since 1951. In the Figure 3 the image of the Venus on the plate 181 DLA is presented.

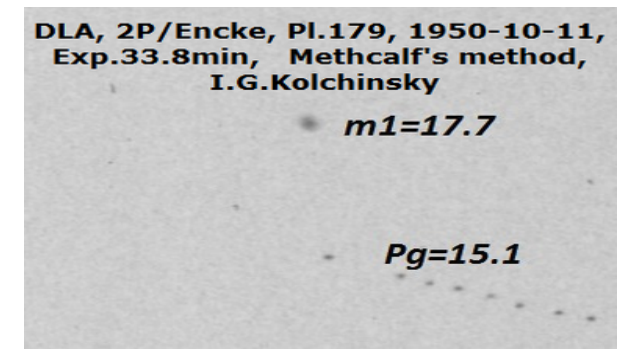

Figure 2: Comet Encke on the plate 179 DLA

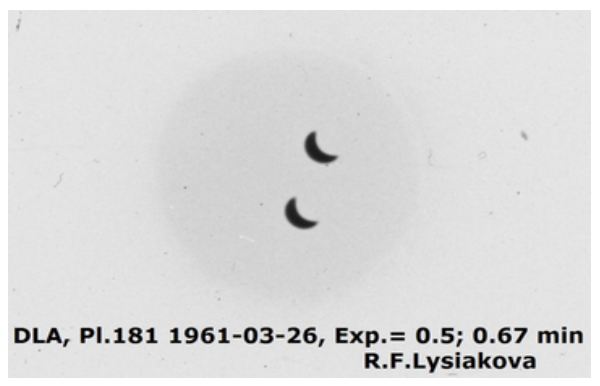

Figure 3: Venus on the plate 181 DLA

Table 2: Distribution of the number of plates according to the observation programs and the telescopes

\begin{tabular}{|lr|r|l|l|l|}
\hline $\begin{array}{l}\text { Object Type / } \\
\text { of plates }\end{array}$ & DLA & DWA & DSA & Other \\
\hline $\begin{array}{l}\text { Planets and their natu- } \\
\text { ral satellite }\end{array} \mathbf{2 0 6 5}$ & 1508 & 263 & 17 & 277 \\
\hline Moon & $\mathbf{6 5 7}$ & 649 & - & 8 & - \\
\hline Minor planets $\mathbf{2 0 3 7}$ & 935 & 1063 & 39 & - \\
\hline Comets $\mathbf{1 4 2 2}$ & 197 & 693 & 366 & 166 \\
\hline Artific. Satellite $\mathbf{3 0 6 4}$ & - & 3062 & 2 & - \\
\hline
\end{tabular}

The distribution of the number of plates with the SSB according to the telescopes and the observation programs is given in the Table 2 and Figure 4.

Table 3 gives the distribution of the number of plates obtained by the different observers in accordance with the observation period at the "home" telescopes. Additionally 47 plates were received by the following observers: 9 L.L.Novoborskaya, 8 - A.N.Kur'yanova, 8 - D'jakonova, 6 - T.Ye.Majzlina, 6 - Ya.T.Kapko, 5 - L.K.Pakuliak, 5 A.S.Duma; 31 plates were received one by one and $14-$ by unknown observers. 


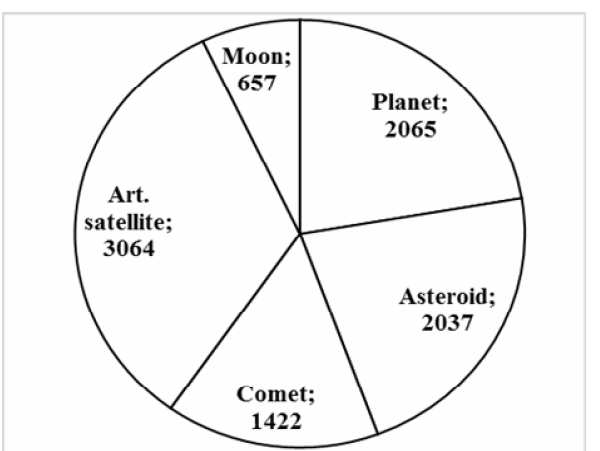

Figure 4: Distribution of the number of plates according to the observation programs.

Table 3: Observers at DLA, DWA, DSA

\begin{tabular}{|l|r|r|}
\hline \multicolumn{1}{|c|}{$\begin{array}{c}\text { Observers, instruments } \\
\text { 1-DLA, 2-DWA, 3-DSA) }\end{array}$} & \multicolumn{1}{l|}{$\begin{array}{l}\text { Pla- } \\
\text { tes. }\end{array}$} & $\begin{array}{l}\text { Observation } \\
\text { period }\end{array}$ \\
\hline L.M.Kizyun (Miz') (1+2) & \multicolumn{1}{|c|}{1939} & $1960-2005$ \\
\hline E.M.Sereda (1+2) & 1180 & $1959-1987$ \\
\hline I.V.Gavrylov (1) & 816 & $1954-1966$ \\
\hline Yu.I.Safronov (2) & 646 & $1978-1991$ \\
\hline G.V.Moroz (1+2) & 595 & $1967-1983$ \\
\hline A.B.Onegina (1+2) & 470 & $1953-1977$ \\
\hline S.P.Major (1+2) & 410 & $1959-1986$ \\
\hline Yu.M.Ivashchenko (2) & 367 & $1983-1992$ \\
\hline O.M.Yizhakevych (2) & 347 & $1978-1988$ \\
\hline Yu.V.Sizonenko (2) & 287 & $1978-1997$ \\
\hline R.F.Lysiakova (1) & 196 & $1959-1965$ \\
\hline I.M.Demenko (1) & 114 & $1960-1971$ \\
\hline I.V.Kulyk (Ledovskaya) (1+2) & 114 & $1982-1988$ \\
\hline I.G.Kolchinsky (1) & 113 & $1950-1963$ \\
\hline R.I.Chupryna (1+3) & 112 & $1951-1956$ \\
\hline G.A.Garazdo-Lesnykh (3) & 103 & $1964-1970$ \\
\hline M.R.Bocharova (2) & 96 & $1985-1990$ \\
\hline V.K.Rosenbush (Fartushnaya) & & \\
(2+3) & 95 & $1976-1979$ \\
\hline V.I.Stupin (3) & 92 & $1964-1968$ \\
\hline V.V.Golovnya (2) & 92 & $1985-1996$ \\
\hline S.V.Shatokhina (1+2) & 76 & $1984-1989$ \\
\hline Yu.K.Philippov (1) & 63 & $1971-1974$ \\
\hline M.L.Divinskij (1) & 44 & $1969-1972$ \\
\hline A.V.Bolbochanu (1) & 37 & 1960,1975 \\
\hline I.G.Zhdanova (3) & 36 & 1954 \\
\hline A.E.Rosenbush (3) & 33 & 1974 \\
\hline G.A.Ivanov (1+2) & 25 & $1974-1983$ \\
\hline A.A.Gorynia (1) & 22 & $1950-1953$ \\
\hline E.A.Herz (1+2) & 21 & $1973-1981$ \\
\hline T.A.Azarnova (3) & 18 & 1950,1954 \\
\hline N.V.Kharchenko (1) & 17 & 1982 \\
\hline O.V.Nazarenko (2) & 17 & 1987 \\
\hline G.I.Balan (3) & 16 & 1970 \\
\hline S.V.Kaltygina (2) & 16 & $1984-1986$ \\
\hline F.I.Lukatskaya (3) & 15 & $1956-1963$ \\
\hline A.F.Pugach (3) & 15 & $1963-1964$ \\
\hline V.S.Kysljuk (1) & 15 & $1963-1970$ \\
\hline D.P.Duma (Kotovych) (2) & 14 & $1978-1983$ \\
\hline V.P.Taraschuk (3) & 13 & $1964-1966$ \\
\hline A.I.Yatsenko (1+2) & 13 & $1974-1983$ \\
\hline
\end{tabular}

Table 4: Observers at the "others" telescopes.

\begin{tabular}{|l|c|l|}
\hline Observers & Plates. & Obs.period \\
\hline Yu.V.Sizonenko & 100 & $1983-1990$ \\
\hline S.P.Major & 98 & $1986-1991$ \\
\hline $\begin{array}{l}\text { I.V.Kulyk(Le- } \\
\text { dovskaya) }\end{array}$ & 89 & $1985-1990$ \\
\hline S.V.Shatokhina & 46 & $1987-1991$ \\
\hline G.N.Khimeridze & 46 & 1990 \\
\hline O.M.Yizhakevych & 23 & $1988-1991$ \\
\hline E.M.Sereda & 32 & 1986,1988 \\
\hline K.O.Major & 9 & 1986 \\
\hline
\end{tabular}

Table 4 gives the distribution of the number of plates obtained by individual observers in accordance with the observation periods at the Z-600, DAZ, CA, 2CAA, SCHC, 53/Sch and BYU telescopes.

Basically photographic observations of the SSB at MAO NAS of Ukraine have been finished in 1996. However, the date of complete cessation of the optical observations is 2005, when L. M. Kizyun (record holder in observations) completed observations of artificial satellites.

\section{Catalogs of positions of the Solar system bodies}

The results of elaborating of old observations, their analysis and methods of processing are presented in numerous publications (Kolchinskii \& Onegina, 1977; Yizhakevych et al, 2001, Golovnya, 2000, 2001). However, the accuracy of the SSB positions based on old stellar catalogs is currently insufficient to refine modern motion theories and to reveal subtle effects in satellite motions. Creating the LINUX/MIDAS/ROMAFOT software and archive of digitized books - UkrVO JDA at MAO NASU made it possible to conduct a new astrometric treatment of some SSBs (Andruk et al, 2005, 2012, Protsyuk et al, 2014a, 2014b; Golovnya, 2010). On the basis of the digitization and reduction in a system of ICRS with a reference catalogue of TYCHO-2, new catalogues of the SSB positions have been created (Golovnya, 2000, Shatohina et al., 2016, 2017; Vavilova, 2016; Vavilova et al, 2014, 2017; Kazantseva et al, 2015; Protsyuk et al, 2015, 2016. 2017; Yizhakevych et al, 2014, 2015, 2017).

Table 5: The results of processing of the SSB observations

\begin{tabular}{|l|r|r|l|}
\hline Name of SSB & $\begin{array}{l}\text { Pla- } \\
\text { tes }\end{array}$ & $\begin{array}{l}\text { Posi- } \\
\text { tions }\end{array}$ & $\begin{array}{l}\text { Observation } \\
\text { period }\end{array}$ \\
\hline Venus & 378 & 284 & $1959-1985$ \\
\hline Moon & 657 & $\approx 345$ & $1950-1980$ \\
\hline Mars+2sat (1318+831) & 859 & 2149 & $1963--1988$ \\
\hline J6, J7, J8 & 32 & 33 & $1987-1990$ \\
\hline 8 sat. of Saturn & 209 & 1385 & $1961-1990$ \\
\hline Uranus + 4 sat. (61+56) & 33 & 117 & $1963-1990$ \\
\hline Neptune+ 1 sat. (43+7) & 29 & 50 & $1963-1990$ \\
\hline Pluto & 25 & 25 & $1961-1982$ \\
\hline Minor planets & 2037 & $\approx 1643$ & $1950-1996$ \\
\hline Comets & 1422 & $\approx 447$ & $1950-1996$ \\
\hline Artificial satellite & 3064 & 6024 & $1977-1981$ \\
\hline
\end{tabular}


Table 5 shows the distribution of the number of plates and number of positions received for the corresponding objects of the Solar system in the specified periods. Some positions of Minor planets are published in the "Manuscripts of VINITY", so the number of the positions in the table is given approximately.

Except for the plates with the SSB, the JDA includes about 18 thousands of direct sky area plates, which have been taken for various astronomical projects. Those plates also contain large number of the images of minor planets and others Solar system bodies (Shatohina et al., 2017).

\section{Conclusions}

The MAO NAS of Ukraine was the initiator and a participant of the international scientific programs and projects: astrometric observations of planets and their natural satellites, selected minor planets, minor planets, comets, Moon, artificial satellites.

9245 photographic plates with the images of the SSB were obtained and stored in the UkrVO JDA. For half a century, 12502 positions of the Solar system bodies were calculated and their catalogs were created.

The collected data were processed and used by IPA, Sternberg Institute and IMCCE, Minor Planet Center for the improvement of the ephemerides of minor planets, planets and their natural satellites, comets.

The result of many years of work has become a long, homogeneous series of observations of various Solar system bodies, obtained with the greatest possible accuracy and became the basis for further astrometric research. Some observations were made during the space missions such as VEGA, FOBOS, CORONAS.

\section{References}

Andruk V.M., Vid'Machenko A.P., Ivashchenko Yu.M.: 2005, Kinem. Phys. Celestial Bodies, Supl.N5, 544.

Andruk V.M., Ivanov G.A., Yatsenko A.I. et al.: 2012, Bull. T. Shevchenko Nat. Univ. Kyiv., Astron. 48, 11.

Duma D.P., Kizyun L.N.: 1972, Astr. Astrofiz, 16, 25.

Duma D.P. et al.: 2000, Report of $N A N U$, Avail.et: http://www.mao.kiev.ua/docs/zvity/2000_tem173_Dum a_Major, pp.40, (in Ukrainian).

Emelianov N.V. et al.: 1999, VizieR On-line Data Catalog: $J / A+A S / 139 / 47$. 1999A\&amp;AS..139...47E.

Emelyanov N. V. et al.: 2006, CR, 44, 2, 128.

Gavrilov I.V., Kislyuk V.S.: 1971, The Moon, 2, 363.

Gavrilov I.V. et al.: 1980, Report of AN USSR, et: http://www.mao.kiev.ua/docs/zvity/1980_zv_tema32_G avrilov_Major.pdf, pp.89, (in Russian).

Golovnya V. et al.: 2000, On-line Data Catalog: DBGPA 3/01. Avail.et: http://gua.db.ukr-vo.org/starcatalogs.php? whc $=$ mphdcat.

Golovnya V. et al.: 2001, On-line Data Catalog: DBGPA 3/05. Avail.et: gua.db.ukr-vo.org/starcatalogs.php?whc= asteroids.

Golovnya V., Andruk V., Yatsenko A.: 2010, Journal of Physical Studies, 14, N2, 2902, (in Ukrainian).

Kazantseva L.V., Shatokhina S.V., Protsyuk Yu.I. et al.: 2015, Kinem. Phys. Celestial Bodies, 31, 1, 37.

Kiseleva T.P. et al.: 2007, Solar Syst. Research, 41, 1, 72.
Kislyuk V.S. et al.: 1985, Report of AN USSR, Avail. et: http://www.mao.kiev.ua/docs/zvity/1985_Kislyuk_Maj or.pdf, pp.62, (in Russian).

Kislyuk V.S. et al.: 1990, Report of AN USSR, et: http://www.mao.kiev.ua/docs/zvity/1990_tema86_Kisl yuk_Major.pdf, pp.28, (in Russian).

Kislyuk V.S. et al.: 1995, Report of NANU, Avail. et: http://www.mao.kiev.ua/docs/zvity/1995_zv_tema102_Kislyuk_Major.pdf, pp.62, (in Ukrainian).

Kizyun L.M.: 2004, KFNT, 20, 6, 540.

Kolchinskii I.G., Onegina A.B.: 1977, Astrometry and Astrophysics, 33, 11 (in Ukrainian).

Kulyk I. et al.: 2013, IMCCE. Int. Workshop NAROOGAIA, Paris Obs., Jun 2012, Paris, France. 153

Major S.P. et al.: 1987, Report of AN USSR, Avail. et: http://www.mao.kiev.ua/docs/zvity/zv_Halley_19831986_Major.pdf, pp.17, (in Russian).

Onegina A.B., Sereda E.M.: 1971, Byull. ITA, 732.

Pakuliak L.K., Vavilova I.B.: 2014, Report of NANU, DR 0110U007859, 288, 145 (in Ukrainian).

Pakuliak L.K.: 2005, DBGPA V2.0, Available et: http://gua.db.ukr-vo.org/archivespecial.php.

Protsyuk Yu.I, et al.: 2014a, Odessa Astron. Publ., 27, 61.

Protsyuk Yu.I. et al.: 2014b, Odessa Astron. Publ., 27, 63.

Protsyuk Yu. et al.: 2015, Odessa Astron. Publ., 28, N2, 204.

Protsyuk Yu. et al.: 2016, Odessa Astron. Publ, 29, 147.

Protsyuk Yu.I. et al.: 2017, Science and Innovation, 13, N1, 89.

Sereda E.M., Izhakevich E.M.: 1978, A i A, 36, 72.

Sergeeva T.P., Golovnya V.V., Sergeev A.V. 2005, Kinem. i Fizika Nebesnykh Tel, Suppl, 5, 577.

Sergeeva T.P. et al.: 2004, Report of NANU, DR 0101U006099, 198,121, (in Ukrainian).

Sergeeva T.P. et al.: 2007, Report of NANU, DR 0105U000547, 222, 101 (in Ukrainian).

Sergeeva T.P. et al.: 2010, Report of NANU, Avail. et: http://ukr-vo.org/documents/zvit_249_full.pdf, pp.121.

Shatohina S. et al.: 2016, Bull. T.Shevehenko Nat.Univ. Kyiv.Astron., 53, 24 (in Ukrainian).

Shatokhina S. et al.: 2017, Bull. T.Shevchenko Nat.Univ. Kyiv.Astron., 55, 6 (in Ukrainian).

Vavilova et al.: 2014, Odessa Astron. Publ., 27, 65.

Vavilova I.B.: 2016, Odessa Astron. Publ., 29, 109.

Vavilova I.B. et al.: 2017, Astroinformatics, Proc. of the IAU Symposium, 325, 361.

Yatskiv Ya.S. et al.: 1986, Report of AN USSR, d. r. No.01.83.0073650, (in Russian).

Izhakevich E.M. Shatokhina S.V., Golovnya V.V. et al., 2001, Kinem. i Fizika Nebesnykh Tel, 17, 1, 65.

Yizhakevych O. et al.: 2014, Odessa Astron. Publ., 27, 67.

Yizhakevych O.M., Andruk V.M., Pakuliak L.K.: 2015, Odessa Astron. Publ., 28, 213.

Yizhakevych O.M. et al.: 2017, Kinem. Phys. Celestial Bodies, 33, N 3, 70. 